\title{
LO TESTIMONIAL COMO NOVEDAD EN LA PRIMERA ÉPOCA DE LA REVISTA CRISIS (1973-1976)
}

Ramiro Esteban Zó ${ }^{39}$

RESUMEN: La revista Crisis, como plataforma intelectual y cultural de la Argentina de buena parte de la segunda mitad del siglo XX en Argentina, se publicó en una primera época entre mayo de 1973 y agosto de 1976 durante cuarenta números. Esta publicación fijó ciertas tendencias en materia intelectual, cultural, literaria, artística y política. En ese sentido, esta revista trató de poner en discusión la novedad del testimonio como subgénero literario. Este trabajo intenta dar cuenta de los procesos de legitimización, difusión, consolidación y discusión del testimonio como novedad genológica en el campo cultural latinoamericano del siglo XX.

Palabras clave: Crisis; Testimonio; Lo nuevo; Redes intelectuales.

RESUMO: A revista Crisis, como plataforma intelectual e cultural da Argentina durante grande parte da segunda metade do século XX na Argentina, foi publicada em um primeiro período entre maio de 1973 e agosto de 1976 para quarenta questões. Esta publicação definiu certas tendências em questões intelectuais, culturais, literárias, artísticas e políticas. Nesse sentido, esta revista tentou colocar em discussão a novidade do testemunho como subgênero literário. Este artigo procura explicar os processos de legitimação, disseminação, consolidação e discussão do testemunho como novidade genológica no campo cultural latino-americano do século XX.

Palavras-chave: Crisis; Testemunho; O novo; Redes intelectuais.

39 Profesor Adjunto de Literatura Latinoamericana II y Profesor Adjunto de Práctica Docente (Letras) de la Facultad de Filosofía y Letras, UNCuyo. Investigador de la UNCuyo. Editor de los Cuadernos del CILHA. 


\section{Introducción}

Toda intromisión de lo novedoso, lo nuevo, la novedad trae consigo una tensión sociocultural que dispara un diverso tendido de redes intelectuales. Víctor Godgel (2013) considera que "la experiencia de lo nuevo puede ser analizada desde dos perspectivas distintas" (Godgel, 2013, p. 19) que a menudo colisionan y entran en conflicto:

1) La primera podríamos darle el nombre de "la importancia de la novedad": puesto que "preserva el atractivo de la novedad -con sus connotaciones modernas de mejora, liberación, originalidad, etc. $-\mathrm{y}$, por ende, mantiene abierta la posibilidad de entender la importancia que este atractivo tuvo y sigue teniendo sobre los sujetos" (GODGEL, 2013, p. 19).

2) La segunda, cabría llamarla como "la incertidumbre por la novedad": ya que "produce cierto escepticismo hacia lo (supuestamente) nuevo y lo entiende, antes que nada, como una suerte de ilusión: simple efecto retórico o, en todo caso, variación del uso y la función de elementos culturales ya disponibles" (GODGEL, 2013, p. 19).

Estas dos formas de percibir y sentir lo nuevo, la asimilación y el rechazo, la aceptación y la duda, una pulsión hacia adelante y una dirección al pasado, dan cuenta de una tensión dialéctica que la irrupción de textos y discursos testimoniales en las páginas de la revista argentina Crisis tanto en contexto sociocultural argentino como latinoamericano no quedó exenta, forjando una red de lectores, editores y escritores de lo testimonial latinoamericano.

De esta forma, es dable decir que los textos públicos de los intelectuales, poetas, militantes y políticos sean poesías, dibujos, cartas, crónicas, entrevistas, novelas, entre otros, han sido elaborados de manera colectiva dentro de la red de lo testimonial en la que se encuentran. Tanto los portadores de lo nuevo (los editores de Crisis, los lectores del semanario, los autores colaboradores) como aquellos defensores del status quo (el público y la crítica más conservadora tanto argentina como del resto de América Latina) forman parte de la misma red intelectual, es por ello que se generan tensiones en la misma red que se cristalizan en sus textos públicos. 
En ese sentido, la revista Crisis es una verdadera plataforma intelectual y cultural de la Argentina de buena parte de la segunda mitad del siglo XX en Argentina. Este órgano editorial se publica en una primera época entre mayo de 1973 y agosto de 1976 durante cuarenta números. Fundada por Federico Vogelius que fue su director ejecutivo y su director editorial fue Eduardo Galeano; en el número 12, de abril de 1974, se incorpora Aníbal Ford como secretario de redacción junto a Juan Gelman. En abril de 1986 la revista comienza su segunda época con algunos de sus antiguos colaboradores como Galeano y Vogelius.

Desde su nacimiento la revista se gestó con un carácter siguiendo a Ponza (2016) de "publicación político-cultural independiente de organizaciones político-militares" (PONZA, 2016: 7). Esta publicación fijó ciertas tendencias en materia intelectual, cultural, literaria, artística y política con un programa estético-políticocultural que "funda su legitimidad cultural sobre un reenvío al pasado que confiere sentido a las pugnas con el presente" (SONDEREGUER, 2011, p. 10).

Si bien la revista no tuvo una estructura homogénea en secciones fijas ni presentó un manifiesto inaugural, esta publicación intenta poner en discusión la novedad del testimonio como subgénero literario. Este trabajo intenta dar cuenta de los procesos de legitimización, difusión, consolidación y discusión del testimonio como novedad genológica en el campo cultural latinoamericano del siglo XX.

\section{El papel de lo testimonial en Crisis}

La revista Crisis poseía un grupo de lo más heterogéneo de colaboradores que respondían a diferentes orígenes, trayectorias y afinidades políticas (asociadas a corrientes de la izquierda, el peronismo y el nacionalismo populista), provenientes tanto del campo de la literatura y el periodismo como del ámbito universitario.

Esta publicación se diferencia de otras revistas culturales argentinas contemporáneas, puesto que se llegó a posicionar como un proyecto editorial periodístico y profesional apuntada al gran público lector no a una élite cultural. 
Su programa cultural y literario incluía tanto la revisión y relectura de la historia argentina como la de su tradición literaria y cultural, con un fuerte énfasis en la revaloración de los llamados géneros menores (la tradición del género policial y el folletín, la telenovela, el circo y el teatro criollo y el testimonio).

En ese sentido, esta resignificación de los géneros menores se enmarca en una tendencia a lo que Cohen Imach (1994) denominan "recuperación de la cultura popular" vigente también en otras revistas culturales de principios de los setenta. Los mecanismos de legitimación, resignificación y valorización tienden a establecer un proceso de recuperación del campo popular pergeñado por esta revista como verdadera plataforma revisionista, legitimadora y recuperadora histórica, ideológica y política de lo popular. Así lo expresa la propia Cohen Imach (1994):

La revista no sólo recupera a través de investigaciones las subculturas dominadas sino que se convierte en protagonista del trasvase de intelectuales a los sectores populares o marginados; el equipo sale en busca de estos interlocutores a la calle o a los caminos, con el fin de testimoniar trozos de su imaginario, de sus discursos poéticos alejados de lo oficial. En cualquiera de estas vertientes, su intención es subrayar las posibilidades creativas de tales grupos, así como legitimar su condición de sujetos activos presentando sus voces muchas veces sin mediaciones (COHEN IMACH, 1994, p. 278).

En ese sentido, el ideologema de Crisis pretende "anular los límites existentes entre arte popular y arte de vanguardia" (COHEN IMACH, 1994, p. 279).

En ese marco, lo testimonial se introdujo en esta verdadera plataforma cultural que representó Crisis como una verdadera 
novedad dentro de este proceso de legitimación social, política e ideológica que tuvo su correlato genérico al pretender revalorizar el subgénero testimonial a menudo cultivado en ciernes en buena parte de nuestra literatura latinoamericana.

\section{Lo testimonial como novedad en Crisis}

El análisis de la incorporación de lo testimonial en Crisis debe enmarcarse en este proceso de la revista de hacer circular ideas, conceptos, géneros y textos "fuera de los manuales", en una especia de dirección contracultural hegemónica. Así lo expresa Aníbal Ford en el número 18:

El rol particular que juegan los procesos culturales en la liberación de los países del Tercer Mundo los ha llevado a plantearse los problemas de política cultural desde una perspectiva muy diferente a las de las metrópolis. Estos planteamientos, de los cuales el peronismo fue precursor en muchos aspectos por el énfasis puesto en la cultura popular, la importancia dada a los medios y el trabajo cultural y su concepción antropológica de la cultura, son parte de un proceso donde queda mucho por elaborar y revisar. Pero lo cierto es que lo afirmado al principio exige no sólo no marginar vastas zonas de la cultura, como siempre se ha hecho, sino también integrar en el análisis los aspectos laborales, legislativos, económicos, que influyen o determinan la producción cultural. Por esto, el objetivo de Crisis no es el de reproducir los esquemas de las revistas literarias tradicionales. Tanto como seguir el 
proceso literario, interesa analizar los problemas de la infraestructura cultural, recoger los testimonios más escondidos y marginados de la cultura popular, atender a las formas masivas de comunicación e información (CRISIS, n. 18 , octubre 1974, p. 69).

El texto no aparece con la firma en la revista, pero tras una conversación entre María Sonderéguer y Ford, éste último confirma su autoría de este ensayo de la sección "Noticias, una experiencia de periodismo popular".

La novedad de lo testimonial ya se configura en los primeros volúmenes de la revista, puesto que en el número 2 de Crisis de junio de 1973 aparece el poema "La verdad es la única realidad" de Francisco Urondo que claramente configura un caso de poesía testimonial elaborada desde el cautiverio en la cárcel de Villa Devoto en abril de 1973. El texto explora el espacio intramuros de la experiencia del encierro y la prisión visualizada metonímicamente a través de la reja se yergue como la expresión de un discurso que intenta testimoniar los vejámenes sufridos.

Paco Urondo, vuelve a aparecer en las páginas de Crisis de la mano de un "fragmento anticipatorio" de su libro testimonial $\mathrm{La}$ patria fusilada (1973) en forma de entrevistas a María Antonia Berger, Alberto M. Camps y René Haidar, únicos sobrevivientes de la masacre del 22 de agosto de 1972 o más conocida como la Masacre de Trelew, es decir, del fusilamiento de prisioneros tras el masivo intento de fuga guerrillera del penal de Rawson en agosto del 72. La revista Crisis para ir afianzando este proceso no solo de divulgación y sociabilización del subgénero testimonial entre las redes de lectores, autores, editores e intelectuales que aglutinaba este suplemento sino también de legitimización social de este producto cultural como es el testimonio, proyecta una edición del libro y la anticipa con un fragmento antecedido por la siguiente presentación:

En la noche del 24 de mayo, los presos políticos de Villa Devoto ocuparon las 
plantas celulares, hicieron pintadas, confeccionaron banderas y se prepararon para salir en libertad. Desde las 9 de esa noche hasta las 4 de la madrugada del 25, en un clima de fiesta creciente -insomnio, canciones y consignas-. Francisco Urondo recogió estos testimonios en una celda del celular $\mathrm{N}^{\circ} 2$ (CRISIS, n. 4, agosto 1973, p. 63).

Este libro salió publicado por la misma editorial Crisis en una edición de 140 páginas con un dibujo a pluma salpicado de sangre en la tapa, un hombre arrasado por la descarga. El pie de imprenta de la edición dice lo siguiente: "Primera edición, 15 de agosto de 1973, 10.000 ejemplares; 2da., 30 de agosto de 1973, 5000 ejemplares; 3 ra. Edición, 17 de septiembre de 1973, 5000 ejemplares”. Es decir, una tirada de 20000 ejemplares en el lapso de un poco menos de un mes, proceso editorial que continúa potenciando y optimizando este proceso de implantación de la novedad del testimonio en el contexto epocal no solo argentino sino latinoamericano. Tanto el "fragmento anticipatorio" en Crisis como la posterior publicación del libro en el sello editorial de la revista posibilitan encadenar una ingeniería de divulgación y expansión del testimonio entre la red cultural que engloba la publicación ${ }^{40}$.

${ }^{40}$ En el número 5 de Crisis del septiembre de 1973, en las primeras páginas hay una suerte de aviso publicitario de la edición de La patria fusilada con una foto de la portada del libro y con el siguiente slogan publicitario: "Es el relato hecho por los sobrevivientes de Trelew con austeridad y grandeza. Ediciones Crisis se honra presentado este libro a un año de la masacre que los argentinos ¡NO SE PUEDEN OLVIDAR! La primera edición se vendió en una semana. ESTÁ LISTA LA 2a EDICIÓN” (en negrita en el original). Es claro que lo testimonial no solo se evidencia en las páginas de Crisis como una novedad en el caso de estos discursos fruto de represión dictatorial argentina, sino que también da cuenta de un verdadero boom editorial de lo testimonial. La masacre de Trelew es una suerte de "hilo conductor testimonial" que va atravesando varios de los números de Crisis no solo en los volúmenes 3, 4 y 5, sino también en el número 17 de septiembre de 1973, en el que se publica un 
En este proceso de revaloración de un subgénero desconocido y en cierta medida marginal entre los lectores latinoamericanos Crisis toma la delantera a nivel de novedad al incluir ya en el número 3 de su primera época, en agosto de 1973, una sección intitulada "Hecho en prisión" instala ya no solo el subgénero testimonial como una novedad sino también que presenta una verdadera apertura de la noción de testimonio albergando cartas, pequeñas crónicas y dibujos de prisioneros políticos argentinos. Lo testimonial no solo funciona dentro de la revista como una novedad que se inserta, divulga, promociona, discute y difunde, sino que también de alguna forma este semanario establece desde su línea editorial una conciencia genológica y discursiva de lo testimonial flexible y dinámica apropiándose de un crisol de discursos tendientes a dar cuenta de los sufrimientos de presos y víctimas de crímenes de Estado.

La presentación de esta sección es un verdadero manifiesto editorial en torno a esta difusión de lo testimonial:

Los textos que Crisis ofrece en las páginas que siguen, fueron escritos, por diversos presos políticos argentinos en estos últimos años. Han sido recogidos y seleccionados con la colaboración de Vicente Zito Lema y María Bedoyan. Cartas, poemas, crónicas y dibujos, deslizados de contrabando por debajo de las puertas de las cárceles en oportunidades diversas, brindan hoy el mejor testimonio posible sobre una época que ha quedado atrás para la Argentina pero que sigue siendo, en varios países latinoamericanos, la noche de cada día. Estas voces, sumados todas

testimonio de una madre de un preso de Trelew recogido por Eduardo Giaccio que describe la vida en prisión desde un patetismo y una intensidad significativa a punto de tal de considerar sus existencias como las de unos "topos" desacostumbrados a la luz solar o "locos enchalecados" víctimas de una reclusión inhumana. 
en una sola voz, sin estrellato ni afanes individuales de consagración, son también literatura. Porque iluminan la realidad con eficacia y a veces con fuerza desgarradora. Porque nos ayudan a comprender un poco mejor qué somos, qué podemos ser, para qué peleamos (CRISIS, n. 3, julio 1973, p. 3).

En este manifiesto es clara la conciencia genérica que se tienen en la revista puesto que se tiene certeza editorial que se están difundiendo discursos que por más que tengan atisbos de narrativa testimonial no dejan de ser recortes ficcionales de una experiencia traumática. Y es que si es que la víctima-testigo-autor considere o no más cerca de lo ficcional su discurso, lo que no entra en discusión es que su relato es una "memoria viva" de lo sucedido que intenta reactualizar para concientizar a los lectores no solo de los vejámenes producidos sino también para que estos hechos no vuelvan a sucederse jamás.

Incluso la forma de presentación gráfica jugando desde los titulares de los textos apunta a divulgar la sintomatología del cautiverio: cómo se sufrió, qué padeció, qué sintió, qué percibió y todo el resto de una plasmación de toda la sensibilidad carcelaria manifiesta verbal o pictóricamente.

El primer texto de primera sección "Hecho en prisión", verdadera inauguración de esta plataforma textual de difusión testimonial dentro de la revista Crisis, lleva el título de "Recibido en la cárcel” y se trate de cartas escritas por Bernabé Gómez a su padre, Luis María en prisión junto a su pareja. Bernabé tenía nueve años y vivía con sus abuelos y le escribe a su padre, preso político en el Instituto de Seguridad y Resocialización (Unidad 6), conocido como el penal de Rawson, espacio carcelario en el que se llevó a cabo la triste masacre de Trelew ${ }^{41}$.

${ }^{41}$ El 15 de agosto de 1972 a las 18:30 comenzó un masivo intento de fuga en el Penal de Rawson, cárcel de máxima seguridad ubicada en 9 de julio 397, Rawson, provincia de Chubut. Si bien algunos militantes lograron el cometido de huir, un gran número de presos fueron detenidos por las fuerzas 
Bernabé escribe tres epístolas fechadas el 15 de junio, el 14 de julio y el 25 de agosto de 1972 que dan cuenta de las tensiones de la dinámica del cautiverio entre "los de afuera" y "los de adentro": la angustia por no verse, el ansia de libertad para su padre y madre recluidos, la percepción de la valentía de su padre y de sus "compañeros" militantes y la insistencia en el poder del "fuego" de la resistencia y la revolución antidictatorial. Llama poderosamente la madurez intelectual y emocional del niño de nueve años que verbaliza desde casi una postura de adulto la agonía de tener a sus padres en prisión.

armadas durante el escape y fueron fusilados el 22 de agosto en la base aeronaval Almirante Zar de Trelew. Más allá del hecho histórico y la crueldad de la situación, la masacre de Rawson luego de la fuga masiva provocó un "nuevo conjunto de regulaciones para detenidos de máxima seguridad" (SEVESO, 2009, p. 160) dentro de una preocupación de los militares de endurecer el sistema penitenciario tradicionalmente organizado para asilar a criminales comunes pero insuficiente a ojos de los militares, para la detención de militantes políticos con alto grado de entrenamiento. Estos cambios en el rigor carcelario, nunca abordados en la historia penal argentina, establecían regulaciones alrededor de toda la vida del prisionero:

desde los cortes de cabello obligatorios hasta la alimentación, lecturas, visitas y actividades físicas. La sección sobre 'las obligaciones de los detenidos' prohibía cantar, gritar, silbar, comunicarse con sonidos acústicos y lenguaje de señas, levantar la voz, participar en 'juegos prohibidos' y 'en general, todo acto u omisión que signifique una alteración del orden reinante'. También se prohibieron los comunicados políticos y las peticiones colectivas, pero probablemente la regulación que produjo mayor conmoción fue la que instauró el confinamiento de los prisioneros en celdas individuales durante la mayor parte del día. El objetivo que los militares perseguían era quebrar la solidaridad y comunicación entre los prisioneros, restringir la circulación de la información política y controlar el contacto entre los detenidos y sus abogados. El nuevo régimen era tan severo que el 30 por ciento de los prisioneros detenidos en seis penitenciarías consumían sedantes y demostraron signos de trastornos psicológicos (SEVESO, 2009, p. 160). 
El siguiente texto en el número 3 de Crisis dentro de esta "sección testimonial" da vuelta la inversión de la subjetividad carcelaria, ya no es "el afuera" que escribe sobre "el adentro" sino que es un verdadero escrito carcelario con el título de "y entonces yo le pedí una bandera". Se trata del comienzo de un relato escrito en prisión por Juan Carlos Bird, militante de la resistencia peronista desde 1955, preso político en prisión durante dieciocho años. Bird si bien fue escrito desde la prisión no verbaliza su cautiverio sino la génesis de su encierro: ¿el por qué de su existencia carcelaria? ¿Cómo llegó a estar entre barrotes? De esta forma, el escritor-testimoniante inicia su relato con su testimonio del bombardeo de Plaza de Mayo, el 16 de junio de 1955. Bird sale de la cooperativa en donde trabajaba y decide ir a esta "columna inaugural y plaza mitológica" (Lerman, $2005)^{42}$ para el pueblo argentino que resulta ser la Plaza de Mayo para presenciar el bombardeo con ánimos no solo de "testimoniar" sino también de "defender" la democracia. Esta situación crítica lo lleva a replantearse su función ciudadana y decide militar y sociabilizar su deseo de resistir:

En ese momento me sacude ese bombardeo, y yo empiezo mi actividad política. Yo estaba emocionado y empecé a tratar de conectarme con alguien, pero no era afiliado, no era nada. Andaba con ganas de hacer, pero como bala perdida. Formábamos algunos grupos,

${ }^{42}$ Lerman realiza una especie de "historia sociológica, política, cultural y antropológica" de la Plaza de Mayo como uno de los escenarios fundamentales de la vida política argentina. Para Lerman este espacio público como una plaza política en donde los individuos concentran un "movimiento de retorno y regreso" al espíritu de Mayo, de reapropiación y reactualización de ese poder popular. Espacio simbólico por antonomasia para la Argentina que cobró diversas isotopías históricas: el 25 de mayo de 1810; la plaza de Rosas; la plaza de la gran aldea; la plaza peronista del '45 a los '70; la plaza de la represión, los desaparecidos, el fútbol y Malvinas; la plaza de los '80 y la plaza sin política, entre otros. Cfr. Gabriel D. Lerman. La plaza política. Irrupciones, vacios y regresos en Plaza de Mayo. Buenos Aires: Colihue, 2005. 


$$
\begin{aligned}
& \text { espontáneamente, cuando las } \\
& \text { manifestaciones, pero uno se veía un } \\
& \text { momento y después perdía el contacto } \\
& \text { (CRISIS, n. 3, 1973, p. 4). }
\end{aligned}
$$

La militancia para Bird vincula a personas con cierta "ideología de resistir": "Poco a poco nos vamos conectando gente que pensábamos lo mismo, que había que pelear" (CRISIS, n. 3, 1973, p. 4). Lo testimonial en este relato, no pasa tanto en la vivencia carcelaria sino en el testimonio de acciones represivas como el bombardeo a Plaza de Mayo y la consecuente reacción de protestas que esto motivó.

Otro relato testimonial encontramos en este número es el escrito "la muerte de mi hijo" de Susana Lima, militante política torturada en la Dirección de Actividades Políticas Antidemocrácticas $(\mathrm{DIPA})^{43}$ disuelta en el momento de publicación de este texto. Este

43 La DIPA fue una "escuela de torturas" (Martínez, 1977) radicada en la calle Moreno 1400 de la Capital Federal comandada por la Policía Federal argentina. Los espacios carcelarios de presos políticos en Argentina incluían no solo cárceles sino también comisarías y centros clandestinos que a menudo funcionaron como verdaderos campos de concentración en los que no solo se recluía los prisioneros sino también se los torturaba. Débora D’Antonio y Ariel Eidelman (2010) ahondan en la tensión del sistema penitenciario y la tortura durante los setenta:

Especialmente al inicio de la década del setenta, la gran cantidad de militantes revolucionarios, antes de la llegada a los establecimientos penitenciarios, era apresada por la Policía Federal, las policías provinciales o el Ejército, lo cual significaba en la mayoría de los casos el paso por la tortura en centros clandestinos, comisarías o en la sede de la policía política. En el caso de la Policía Federal Argentina, la sede de la División de Coordinación Federal, después denominada Superintendencia de Seguridad Federal y allí en las oficinas de la División de Informaciones Policiales Antidemocráticas (DIPA), en Moreno al 1400 de la Capital Federal. En Córdoba, Rosario o Tucumán, la Jefatura de Policía local, en general, con participación de la delegación local de la Policía Federal y en varios casos con intervención de personal del Servicio de Inteligencia del Ejército y de las FF.AA., tras la aprobación de la ley 19.081.42 Tras la detención y tortura, a veces sumado a un secuestro no reconocido durante algunos 
escrito se erige desde una situación límite con la muerte del hijo de la "escritora-militante-testimoniante". El relato tiene forma epistolar a un "Queridísima" que posiblemente sea pariente cercana de Susana Lima y cuya cercanía es vital para compartir el dolor de la pérdida. Además de epístola y carta elegíaca, este escrito de algún modo funciona como "diario de una muerte" que va describiendo brevemente los momentos agónicos del fallecimiento del bebé dando incluso la fecha exacta de su defunción lunes 24. La muerte de un hijo, por un lado, quiebra emocionalmente a la madre y a la mujer por otro, catapulta al infante a categoría de mártir y héroe de la resistencia política de la militancia argentina al morir en prisión:

No sé cómo hablarte. Todo lo que pudo ser y no fue un hijo. El especial. Ese hijo que se nos fue. Como madre, siente un indescriptible dolor. Como mujer, una frustración. Como idealista, un terrible odio hacia el enemigo que lo mató. Te pido que me contestes. No para darme un pésame. No. El mocoso murió; el mocoso es otro mártir y héroe de la causa. Y por ello no se puede dar el insensible y convencional "pésame". No. Necesito las palabras y compañía de los

días, se aplicaba una incomunicación de 10 días para borrar los efectos de la violencia institucional sobre los cuerpos (D'ANTONIO y EIDELMAN, p. 108).

Cfr. Débora D’Antonio y Ariel Eidelman. "El sistema penitenciario y los presos políticos durante la configuración de una nueva estrategia represiva del Estado argentino (1966-1976)", Iberoamericana. América Latina, España, Portugal: Ensayos sobre letras, historia y sociedad, vol. 10, n. 40, 2010, pp. 93-112. Desde un punto de vista ficcional se puede ver el papel de la DIPA en la novela de Tomás Eloy Martínez. La pasión según Trelew. Buenos Aires: Granica Editora, 1974. La tercera edición de esta novela fue quemada en la plaza del III Cuerpo de Ejército, en Córdoba, por la dictadura militar. 
compañeros de ideal (CRISIS, n. 3, 1973, p. 4. Las cursivas son del original).

El testimonio doloroso, agónico y lleno de patetismo de la muerte de un hijo solo tiene consuelo con la fraternidad militante, puesto que no hay lenguaje posible para consolar y contrarrestar el luto. La confraternidad militante, tópico común a menudo en los relatos testimoniales, es el único bálsamo para el dolor de la pérdida de un hijo.

Luego del texto "La muerte de mi hijo" de Susana Luna, nos encontramos en este número de 3 de Crisis con otro texto testimonial "la picana de 220 voltios" de Norma Morello. La propia revista nos contextualiza este relato:

El 16 de diciembre de 1970 secuestran a Martins y Zenteno. Luego integrarán la lista de desaparecidos: Pujals, el matrimonio Verd, Maestre, Misetich. El 30 de noviembre de 1971 desparece Norma Morello. Una activa movilización obtiene el jefe del Regimiento de Goya información sobre su paradero: Morello se encuentra en Buenos Aires, disposición de la Cámara Federal. Su hermana logra verla el 31 de diciembre de 1971. Durante ese mes Norma Morello escribe cinco copias con el relato de las torturas a que fue sometida para hacerlas públicas en caso de que algo le sucediera. Este testimonio, filtrado desde la cárcel, es el que transcribimos (CRISIS, n. 3, 1973, p. 6) $)^{44}$.

\footnotetext{
${ }^{44}$ Norma Morello es uno de los primeros casos de desaparición, detención ilegal y tortura denunciados en la Argentina. A Morello la secuestra el Ejército en 1971 cuando trabaja en la escuela rural 334 como maestra y la liberan cinco meses después, pero luego en 1976 la vuelven a buscar. Luego se exilió un tiempo en Uruguay hasta conseguir los documentos para viajar a España.
} 
El relato testimonial de Morello posee un carácter genológico de diario íntimo de prisión desde su arresto la noche del 30 de noviembre de 1971 cuando estaba alojada en la escuela 534 por su trabajo de maestra rural hasta el episodio de tortura con picana eléctrica durante una sesión de interrogatorio que tuvo lugar el día 9 de diciembre del mismo año. A Morello la trasladan desde la Subprefectura de Goya en avión en espacio no identificado antes de llegar a Rosario. El cronotopo de la tortura no puede ser identificado por la víctima-testigo-escribiente Morello porque según costumbre de estos procedimientos, la víctima es llevada con los ojos vendados y solo puede percibir mediante el tacto o incluso el olfato algunos parámetros para fijar ciertas coordenadas espaciotemporales del lugar a dónde la llevan ${ }^{45}$. Este tránsito, por un lado, representa un movimiento físico que establece este recorrido ${ }^{46}$ :

Para volver a la Argentina en 1984. En 1991, comienza a trabajar hasta la actualidad como orientadora pedagógica en un Proyecto de alfabetización en la villa 31. En sus pasos de la creación del movimiento rural de Goya tuvo el asesoramiento y el apoyo del obispo de Goya, Monseñor Alberto Pascual Devoto, cura miembro de los Sacerdotes para el Tercer Mundo, al que apodaron "el apóstol de los pobres". Morello trabajó en la escuela 497 de la $3^{\circ}$ sección de Goya (septiembre de 1971) y la escuela 534 (noviembre de 1971). Cfr. Mariana Carbajal. "El compromiso", Página12, domingo 24 de julio de 2011. En línea: https://www.pagina12.com.ar/diario/sociedad/3-1729142011-07-24.html Consultado: 10/04/2018.

45 Pamela Colombo reconoce que "el momento en que los detenidosdesaparecidos eran llevados desde el CCDyT al espacio de inhumación clandestina" (COLOMBO, 2013, p. 2), eufemísticamente llamado "traslado", no solo es un movimiento físico, sino que cobra un sentido mayor puesto que "es el resultado de la retroalimentación entre múltiples elementos: espacio, cuerpo, tiempo y percepción” (COLOMBO, 2013: 4). Así, este movimiento por el espacio físico para Colombo implica ciertas características "materiales" que le otorgan cierta particularidad a este movimiento y al espacio donde se produce dicha traslación:

(1) la posibilidad de orientarse/ubicarse en un mundo replegado; 2) el cuerpo "alterado" y su percepción distorsionada; 3) el estatuto epistemológico de las "verdades adjetivadas" que conforman al 
Espacio de trabajo $\longrightarrow$ Espacio del secuestro $\longrightarrow$ CDyT

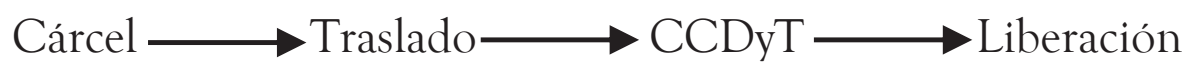

Morello es secuestrada en su lugar de trabajo llevada a un Centro Clandestino de Detención y luego es trasladada a otro Centro en donde es torturada y luego liberada.

Pero, por otro lado, este movimiento tiene una asociación con la espacialidad indeterminada, o lo que Colombo (2013) llama "lo que se cae del mapa": "Se construye un espacio que pretende borrarse a sí mismo, un espacio donde circulan fantasmas, o quizá sería más apropiado decir, un espacio que se vuelve fantasmal al no poder asegurar la presencia de aquellos que lo atraviesan" (COLOMBO, 2013: 9). En el caso de Morello, es clara la relación con esta espacialidad fantasmal que apenas puede transitar incluso desde un sentido de encierro con la figura del túnel angosto que atraviesa. Todo el ambiente espacial cobra sentido para esta detenida-desaparecida para escapar del "tabicado" 47 usado por los militares como elemento

espacio del traslado; y 4) el modo en que el espacio del traslado se adivina en comunidad (COLOMBO, 2013, p. 4).

Cfr. Colombo, Pamela. "Del traslado de detenidos-desaparecidos o el espacio en movimiento: hacia una fenomenología de la percepción distorsionada", Papeles del CEIC. International Journal on Collective Identity Research. 2013, marzo-sin mes. En línea: http://www.redalyc.org/articulo.oa?id=76525696005 Consultado: 10 de abril de 2018.

${ }^{46}$ Pamela Colombo analiza las detenciones y desapariciones en Tucumán teniendo en cuenta ciertas entrevistas de algunos de los involucrados. Y luego de este examen establece un cuadro con los diferentes tipos de traslados. Colombo reconoce que en la investigación de estos traslados se pueden pensar diversas combinaciones por la complejidad de este procedimiento. Para analizar el traslado de Morello hemos seguido dicho estudio. En el apéndice incluimos el cuadro de Colombo. Cfr. Apéndice. Imagen 1.

${ }^{47}$ Colombo describe de esta forma el proceso de "tabicado" de los detenidosdesaparecidos: 
de aislamiento de la víctima. Morello intenta describir con su cuerpo limitado el lugar de tortura:

El avión descendió antes de llegar a Rosario. Al bajar al avión se acercó inmediatamente un coche largo de color celeste, con varios hombres que descendieron y se acercaron al avión.

Dos de ellos subieron. Uno me vendó los ojos [aquí comienza el proceso de limitación y aislamiento del cuerpo de Morello]. Otro me esposó [sigue aquí el proceso de limitación, inmovilización y aislamiento del cuerpo: vendas-ojos, esposas-mano]. Me cargaron al baúl del

En relación a las condiciones en que esos traslados eran realizados, por lo general los detenidos-desaparecidos estaban tabicados - así se les imposibilitaba que vieran "el afuera" -; muchas veces estaban inmovilizados — con sus manos atadas- y en el caso de los traslados del espacio del secuestro al CCDyT se los solía tirar en el piso de los asientos traseros -impidiéndoles que "el afuera" los viera. Las prácticas tendientes a aislar al sujeto comienzan por lo tanto ya durante el traslado: la visión -sentido que monopoliza la aproximación del espacio- les era negada; así mismo no podían tocar lo que los rodeaba ya que solían estar maniatados o tirados en el fondo del vehículo que los transportaba; y tampoco podían hablar. El cuerpo del detenido-desaparecido en el traslado era un cuerpo "limitado", reducido prácticamente a escuchar ruidos y voces (COLOMBO, 2013, p. 7).

Morello es traslada con este procedimiento de tabicado para que no vea afuera e incluso es "escondida" en el baúl de un auto hasta llegar al CCDyT. A ella en primer lugar se le niega la visión con las vendas, en segundo lugar, el tacto libremente porque es esposada y en tercer lugar se le impone silencio no con una mordaza, pero sí haciéndola callar. El cuerpo de Morello es reducido, limitado, silenciado, atado, vendado y luego desnudado para ser por último torturado en este verdadero descensus ad inferos violento e inhumano del secuestro de personas. 
coche y me dijeron: "Si te tocás la venda te doy un tiro". Viajamos unos 20 ó 30 minutos. Me bajaron en una casa de las afueras (hicimos camino de tierra). Me hicieron caminar por un túnel; sólo entraba yo y de costado.

Al salir comenzar los ruidos fuertes de metales y cosas que se movían. La radio fuerte tocaba algo clásico y una voz fuerte me dijo: "Música de ópera... de operación... total por cuatro días locos que vas a vivir..." [a la limitación, inmovilización y aislamiento del cuerpo le sigue la intimidación, turbación y perturbación psicológica mediante amenazas a la víctima]. "Desvestite". Como yo no me desvestía me sacaron ellos la ropa: "No sos la primera que vamos a desnudar", me dijeron, y otras barbaridades más (CRISIS, n. 3, 1973, p. 6).

Pero, a este cuerpo limitado de Morello no solo lo atraviesa el paso violento del traslado, sino que también padece todo el sufrimiento del interrogatorio. Este relato testimonial narra la violencia de la tortura y el trauma que motiva la necesidad de narrar esta experiencia violenta. En el testimonio de Morello se alcanza a vislumbrar cierta característica genológica de este tipo de textos, es una escritura solidaria e incluso terapéutica, puesto que se escribe para soportar el dolor, para sobrevivir al encierro y a la tortura, para curar heridas. Morello con su texto concebido en prisión y filtrado para su consecuente difusión clandestina, revisita, reactualiza y revive sus episodios de tortura para volver a pasar por el pasado inmediato y así enfrentarse con el dolor y e intentar sobrevivir al trauma.

La descripción de la tortura es minuciosa y detallista y da cuenta del dolor corporal y psicológico lacerantes en una graduación de variables siniestras de la vejación: 

a. privación de la vestimenta;
b. inmovilización corporal al estaquear brazos y piernas en una cama;

c. tanteo corporal con la picana sin electricidad;

d. anulación de la posibilidad de gritar mediante un trapo en la boca;

e. uso de la picana con electricidad en las axilas, las piernas, los brazos y la ingle;

d. manoseo de senos y genitales;

e. vuelta al uso de picana con electricidad desde la garganta hasta los genitales;

f. golpe en el vientre con una pelota pesada;

g. acciones de violencia psicológica para enloquecer a la víctima: hacerle desear un vaso de agua, abrir una canilla en momentos de intensa sed;

h. la secuencia de tortura se va repitiendo solo detenida por ciertos interrogatorios, pero con mayor intensidad voltaica de la picana de 110 voltios a 220 .

Eso solo sucedió en el primer día de tortura de Morello. Luego de ocho días de interrogatorios sin tortura y reclusión, la ve un médico y le da penicilina. Y luego se retoman las sesiones de tortura en un ciclo de extracción de información gracias al ejercicio del terror y el dolor ${ }^{48}$.

48 Elaine Scarry, estudiosa de los alcances corporales, psicológicos y ontológicos de la tortura, en una entrevista concedida a Jennifer L. Geddes, reconoce que en los documentos de los 70, como puede ser este relato de Morello, la tortura no solo actúa en el cuerpo de la víctima de un modo físico, sino que desde una visión ontológica para la víctima, la tortura llega a destruir todo su mundo, lo desintegra. Tiene la capacidad de ejercer dolor y destruir el mundo a la vez:

In the cultural context I was looking at, in documents from the 70s, there was a literal acting out of the unmaking of the objects of consciousness and the unmaking of the objectifying power of language. For example, in torture not only did the torturer inflict 
En la misma página en donde comienza el relato de Morello dentro del número 3 de Crisis, se encuentran dos "microtestimonios" de prisioneros políticos de la cárcel de Trelew, muertos en la misma fecha, 22 de agosto de 1972.

El primero lleva el título "la máquina" y es de Carlos Heriberto Astudillo (en la revista solo mencionado Carlos Astudillo). En este "microtestimonio", la víctima-testigo-escribiente verbaliza la tensión de una sesión de tortura, de su propia tortura con la picana eléctrica ${ }^{49}$.

pain, but there was actually a kind of miming of the unmaking of the world by enlisting all the objects of the world into the act. Even if the torturer was using a mechanism such as, let's say, a way of inflicting electrical discharge into the person, he would also refer to chairs and tables and windowsills and baskets and blankets and telephones and all kinds of cultural artifacts, and in that way made the body of the prisoner somehow a kind of agent for not only experiencing its own pain, but for witnessing the dissolution of the made world (Geddes, 2000, p. 79).

[En el contexto cultural que estaba analizando, en los documentos de los años 70, hubo una actuación literal de la eliminación de los objetos de la conciencia y el desmantelamiento del poder objetivador del lenguaje. Por ejemplo, en la tortura el torturador no solo infligió dolor, sino que hubo una especie de remedo de la destrucción del mundo mediante la inclusión de todos los objetos del mundo en el acto. Incluso si el torturador usara un mecanismo como, por ejemplo, una forma de infligir descargas eléctricas a la persona, también se referiría a sillas, mesas, marcos de ventanas, cestas, mantas, teléfonos y toda clase de artefactos culturales, y en ese sentido. De alguna manera, el cuerpo del prisionero fue una especie de agente para no solo experimentar su propio dolor, sino también para presenciar la disolución del mundo hecho.] La traducción nos pertenece.

${ }^{49}$ Carlos Heriberto Astudillo fue uno de los dieciséis reclusos de la base naval Almirante Zar de Trelew fusilados por el ejército argentino, cuya operación estuvo encabezada por el teniente de corbeta Guillermo Roberto Bravo y el capitán Luis Emilio Sosa. El impacto de esta masacre Trelew fue importante a nivel social y una de las repercusiones las encontramos en el movimiento estudiantil argentino. Pablo Augusto Bonavena analiza estas repercusiones en las organizaciones estudiantiles ante el impacto de estos fusilamientos: "El 
El segundo "microtestimonio" es de Alfredo Kohon establece una descripción del ambiente de la tortura para circunscribir exactamente esta situación traumática: 1) la fecha y la hora de la sesión: 6 de enero a las 2 de la madrugada; 2) el lugar: Cárcel de encausados; 3) los grupos de torturadores e interrogadores: de la Policía Federal, de la Policía Provincial y de la Seccional $10^{\circ}$ e 4) incluso especifica dando los nombres de algunos de sus interrogadores: el oficial González y el "policía corpulento" Tapaia o Sapia.

Los testimonios que podemos encontrar en esta sección de "Recibido en la cárcel" del número 3 de la revista Crisis no solo pueden ser: 1) microtestimonios en torno a la tortura, 2) diarios de tortura, 3) cartas de reclusos a familiares o epístolas de familiares a prisioneros, entre otros subgéneros testimoniales. Sino también que se presenta la vinculación entre el presidiario y su defensor: su abogado.

Tal es el caso, de la carta "el alboroto tempranero de las gaviotas" de Ignacio Ikonikoff ${ }^{50}$ a su abogada Mirta Favris, el 16 de

movimiento estudiantil fue sorprendido por la matanza mientras efectuaba una intensa campaña nacional de lucha contra la represión de la dictadura y por la libertad de los presos políticos, muchos de ellos militantes estudiantiles" (BONAVENA, 2011, p. 204). Específicamente para el caso de la muerte de Astudillo, Bonavena reconoce las consecuencias estudiantilespolíticas en Santiago del Estero, ciudad de origen del propio Astudillo:

El 24 de agosto continuaron las repercusiones por los fusilamientos. Durante el entierro de Carlos Heriberto Astudillo y Ana Villareal de Santucho en Santiago del Estero, muertos en la base Almirante Zar, participaron gran cantidad de jóvenes, muchos de ellos estudiantes, lo que lo transformó en un acto político (BONAVENA, 2011, p. 215).

${ }^{50}$ Ignacio Ikonicoff fue un físico santafesino que incurrió en el periodismo científico además de la militancia peronista. A través de la ciencia, Ikonicoff, llegó al periodismo en 1972 para militar en la Lista Marrón y en el Movimiento Nacional contra la Represión y la Tortura, donde también militaban Juan Carlos Dante Gullo, Pirí Lugones y León Ferrari entre otros. Militó en los Comandos Populares de Liberación (CPL). La dictadura del general Lanusse lo encarceló en Rawson y luego la justicia dispuso su 
enero de 1973 en el Instituto de Seguridad y Resocialización de Rawson. El texto de Ikonikoff tensiona entorno a la dinámica "intramuro" y "extramuro": las gaviotas que observa el presidiario desde la ventana representan todo lo positivo que involucra el "extramuro": alegran la vida del recluso con su vuelo libre y despreocupado; despiertan al prisionero con su alboroto vital y la proyección de su sombra en la celda entretiene al prisionero. En cambio, la percepción del espacio "intramuro" es totalmente negativa: prohibido, triste y sombrío. Es interesante, la visión de Ikonikoff que aporta su visión cientificista de la reclusión al proponer un nuevo método científico de contemplación y análisis del aire externo a la cárcel apoyándose en las citas de autoridad de Einstein y Böse:

Me permito una digresión: mirando el color del amanecer y del crepúsculo y comparándola con el azul del mediodía, Einstein y otro que creo que fue Böse calcularon ¡el número de moléculas por litro de aire! Realmente hay que ser muy buen tipo y sobre todo infinitamente pacífico y tranquilo para inventar un motivo de trabajo científico contemplando la puesta del sol (CRISIS, n. 3, 1973, p. 6).

excarcelación días antes del 25 de mayo de 1973. Altruista y solidario, volvió de motus propio a la cárcel de Devoto para salir con todos sus compañeros. Dijo: "salimos todos o no sale nadie". Cuando los CPL se sumaron a Montoneros, él también lo hizo. A la edad de 35 años Ignacio Ikonicoff, fue secuestrado-desaparecido, en la localidad de Marcos Paz, el 12 de junio de 1977, juntamente con otros compañeros con los que formaba el Partido Revolucionario de los Obreros Argentinos (PROA), todos militantes provenientes del peronismo, la izquierda y la izquierda nacional. Ikonicoff recibió el Doctorado Honoris Causa de la Sorbona. Esta carta tiene lugar en su primera detención. Cfr. Eduardo Blaustein y Martín Zubieta. Deciamos ayer. La prensa argentina bajo el Proceso. Buenos Aires: Colihue, 2006. 
Es notable el proceso de no solo divulgación y difusión de estos discursos testimoniales en esta revista sino el trabajo de edición sobre todo en el caso de titulación de los textos teniendo en cuenta un claro objetivo de captar la atención del lector desde un patetismo propio de la escritura carcelaria. Muchos de los títulos han sido concebidos desde la editorial de Crisis extrayendo fragmentos o frases de los textos que funcionan como "sintagmas gancho" para la atención lectora.

$\mathrm{Si}$ encontramos cartas de familiares a reclusos también podemos hallar epístolas con la relación inversa. Como la carta de Lidia Massaferro de Laferrere, compañera de Francisco Urondo a sus hijos desde el penal de Devoto: "ya es hora de dormir: que sepan que yo estoy pensando en ustedes". Esta carta intenta servir de "cobija" o "frazada" simbólica para estos niños de alguna forma "huérfanos" de la presencia de su madre. Lidia Laferrer intenta llevar tranquilidad a sus hijos y espera una respuesta positiva de ellos a través de dibujos e información de sus vidas para retroalimentarse. Pero el dolor aflora con el recuerdo de su hijo muerto Manolo Belloni a manos de la policía de Tigre en 1973 cuando tenía 23 años y militaba en las FAP (Fuerzas Armadas Peronistas).

No solo cartas, microtestimonios, testimonios, diarios de cárceles encontramos en esta sección sino también podemos hallar dos poemas testimoniales dentro de estos subgéneros testimoniales.

El primer texto lírico es la transcripción de la segunda parte de un poema de Oscar Arbelo en lenguaje "canero". Este texto lleva el título "de vos extraño las cosas chiquitas" y lo dedica a su compañera, el 17 de noviembre de 1972, en la celda 286 del penal de Rawson ${ }^{51}$. Para que pudiese sobrevivir este texto y viralizarse, Arbelo le entrega a Lidia Massaferro de Laferrere que sirve como una "mula comunicativa" que recoge y salvaguarda esta obra inédita para difundirla (ZÓ, 2017). Este texto escrito en lenguaje canero o coa patentiza la vivencia carcelaria desde este argot a menudo críptico. La palabra se encripta en su intención de verbalizar la sensibilidad carcelaria para intentar adaptarse a la conciencia reclusiva, el prisionero político emplea el argot carcelario que asimiló en prisión

${ }^{51}$ Cfr. Texto 1 del Anexo de este artículo. 
para dar cuenta de su realidad. El lenguaje se permea de reclusión, se estigmatiza, se hace paria. Arbelo escribe como "hablan" los que son silenciados, marginados, prohibidos y desparecidos, es el portavoz de los "musulmanes" agambeniamente hablando, de los "no-hombres", los que han tocado fondo, aquellos que sufren la reclusión y no pueden expresarse (ZÓ, 2011).

El segundo poema fue originariamente firmado por "un combatiente peronista", Roberto Coronel lo escribió cuando se enteró que Diego Ruy Frondizi y Manuel Belloni habían sido asesinados en el Rincón de Milberg. Este poema escrito en noviembre de 1971 en la cárcel de Devoto da cuenta del ambiente carcelario que lo transforma en un ser inútil al presidiario en permanente estado de rabia, un ser destinado a estar arrojado en el colchón de su celda sin poder escapar ni transformar su realidad, mientras que en el espacio "extramuro" se fusilan a compañeros del recluso ${ }^{52}$. Así mismo, en este texto se verbaliza la dinámica de persecución de militantes por parte del Ejército en un largo racconto entre guiones dentro del poema. La víctima-testigo-poeta resemantiza su encierro complejizando las coordenadas temporales de su cautiverio: su presente en la celda, el recuerdo de su pasado militante ("nostalgia de un pasado") y un futuro incierto de convivencia con sus camaradas ("el futuro inexorable") en un "método de aprender la realidad" según este yo lírico sufriente y testigo. Coronel le escribe a una lector ideal de este poema: María y despliega "los otros tiempos" de la lucha, la militancia y el encierro.

Además de testimonios verbales en este número 3 de Crisis, encontramos dos testimonios visuales de presos políticos argentinos. El primero de estas imágenes es un autorretrato corporal sin rostro del pintor Franco Venturi, preso en Villa Devoto, en el buque Granaderos y en el penal de Rawson ${ }^{53}$. El dibujo fue elaborado en la celda del buque Granaderos y da cuenta del reducido espacio de la habitación en donde estaba recluido. La militancia peronista del dibujante se ve reflejada en los garabatos que adornan las paredes de

${ }^{52}$ Cfr. Texto 2 del Anexo de este artículo.

${ }^{53} \mathrm{C} f$ r. Imagen 3 del Anexo de este artículo. 
la celda. Representa casi una "fotografía" de cuerpo entero del preso, testimonio pictórico de la reclusión.

El segundo dibujo es un dibujo anónimo que a través de historietas con un personaje felino al estilo del gato Silvestre (Silvester J. Pussycat creado por Friz Freleng) describe la rutina del presidiario desde una óptica casi paródica. El preso es un animal rutinario, sometido y víctima de un sistema deshumanizante ${ }^{54}$.

\section{Conclusión}

Este trabajo intentó comenzar a trazar un examen de todos los procesos de legitimización, difusión, consolidación y discusión del testimonio como novedad genológica en el campo cultural latinoamericano del siglo XX a través de la plataforma cultural que representó la revista Crisis para todo el campo cultural e ideológico de América Latina de los setenta.

Esta revista se gestó con un carácter de "publicación políticocultural independiente de organizaciones político-militares" (PONZA, 2016, p. 7) con un programa estético-político-cultural que "funda su legitimidad cultural sobre un reenvío al pasado que confiere sentido a las pugnas con el presente" (SONDEREGUER, 2011: 10).

Dicho programa incluía tanto la revisión y relectura de la historia argentina como la de su tradición literaria y cultural, con un fuerte énfasis en la revaloración de los llamados géneros menores (la tradición del género policial y el folletín, la telenovela, el circo y el teatro criollo y el testimonio). En ese sentido, el ideologema de Crisis pretende "anular los límites existentes entre arte popular y arte de vanguardia" (COHEN IMACH, 1994: 279). La novedad de lo testimonial ya se configura en los primeros volúmenes de la revista. En este proceso de revaloración de un subgénero desconocido y en cierta medida marginal entre los lectores latinoamericanos Crisis toma la delantera a nivel de novedad al incluir ya en el número 3 de su primera época, en agosto de 1973, una sección intitulada "Hecho en prisión" instala ya no solo el subgénero testimonial como una novedad sino también que presenta una verdadera apertura de la

${ }^{54}$ Cfr. Imagen 2 del Anexo de este artículo. 
noción de testimonio albergando cartas, pequeñas crónicas y dibujos de prisioneros políticos argentinos.

En este trabajo hemos intentado rastrear aquellos testimonios de militantes políticos argentinos en contextos de encierro dentro de procesos cívico-militares de detención durante los años setenta en la revista Crisis. Pero, esta publicación da cuenta de también una noción ampliada de lo testimonial que también abarca a testimonios de militantes latinoamericanos fusilados (n. 15, julio 1974); poesías testimoniales de poetas guerrilleros nicaragüenses y guatemaltecos fusilados por el ejército (n. 7, noviembre de 1973); dibujos, pinturas y postales de niños de villas argentinas (como La Tablada) como salutaciones de fin de año organizadas por el Frente Cultural de Juventud Peronista de La Matanza y la Agrupación Evita de la Rama Femenina como testimonios de la vinculación militancia-educacióninclusión social (n. 9, enero 1974), testimonios de oprimidos en los hospicios argentinos Braulio Moyano, Melchor Romano y Borda recogidos entre 1968 y 1973 por Vicente Zito Lema, con la colaboración de Marcelo Lartigue, Basilo Benítez, Daniel Salvadó, Mario Ancewicz, Roberto Alvarado y Marcelo Pichon Rivière (n. 11, marzo 1974), entre otros testimonios.

En síntesis, de debe reconocer que lo testimonial se introdujo en esta verdadera plataforma cultural que representó Crisis como una verdadera novedad dentro de este proceso de legitimación social, política e ideológica que tuvo su correlato genérico al pretender revalorizar el subgénero testimonial a menudo cultivado en ciernes en buena parte de nuestra literatura latinoamericana. 


\section{Apéndice}

\section{Texto 1}

\section{“de vos extraño las cosas chiquitas”}

De jopende empecé a escolasear la libertad.

A los tevein palmé la primera tumba

Hoy que empiezo a campanear los treinta

pienso, consecuente y zabeca dura

que cuando pegue la vuelta a la tacuaren

si ando pateando la rua

voy a tener

la pepa colgada en el ropero.

Porque aquí, a pesar de la alegría de hoy

todavía hay para rato...

Por eso sin apuro, con paciencia

cebo un mate.

y se lo convido a mi sombra.

Y no me caliento por la pitada que marcó este orsai

y se me breco

por un chamuyo berreta

que no recoge la experiencia laburanta.

17 pirulos

17 pirulos

de bronca y piedra / de ñoca trasnochado y plenario abierto a la yuta / de camani prestada y huelga traicionada / de revolta quemada y de CGT negra / de plan Campos y del Lisandro / del R11 de Rosario y de Huerta Grande / de "ya hemos triunfado" y de Corrientes y Esmeralda / del puesto de Ezeiza y del Utrunco / de ravioladas probadas de cheno y de la calle Gascón / de toma de fábrica y volante clandestino / de tránsfugas que apestan en su tumba y del "hágalo usted mismo" / de técnicas nuevas y checos truchos con papeles polenta.

17 pirulos

y un frangote de ñericompas sin sonrisas que parieron el compromiso / de poner todos los días / mi suerte a pleno 
III

Hoy

de vos extraños las cosas chiquitas

las otras viajan conmigo adentro del bobo.

La pollera cortita

el rouge

el rochepu de sogüe

el namicar juntitos

el darle contra a los salames

el vaso de escabio compartido

Hoy

engomado tuto el yorno

repaso

prolijamente en mi recuerdo

tu ombligo

y de paso

escracho un faso polenta

que tiene sabor a postre bacán

que me permite trenzar

en su hilito de humo

un montón de ideas

sobre el cómo y porqué

de la introducción al raconto. 


\section{Texto 2}

\section{“pregunta llorar putear caminar"}

Estas son las camas esta es la mesa El banco mi puño el de todos desciende con fuerza sobre ellos asentamos nuestros cuerpos inútiles ahí están las once rejas el guardián los muros aquí nuestra impotencia la rabia el dolor el asco las lágrimas sólidas como balas hirientes la piel el puño sube y desciende con fuerza el golpe los golpes la madera golpeando la madera Un largo seco desprolijo coro de golpes Los han capturado María los han herido María y nosotros que haremos en esta tribuna con rejas preguntar llorar putear caminar en círculos con las manos en los bolsillos los dientes apretados acercarnos a la radio esperar los nombres las siglas detalles detalles detalles el prisionero es un inútil en estado de rabia permanente - y corría sin camisas y una bala en la cintura a donde va que piensa la sangre una caricia tibia indiferente los ladridos de los asesinos retumban en su proyecto de fuga estamos con él le abrimos puertas 
lo subimos a un auto

le hacemos torniquetes cubrimos su retirada a tiros

lo escondemos

es pancho

nos derrumbamos en nuestras camas grises

las rejas dejan marcas paralelas

en el cuerpo-

pero recuerdo de él los otros tiempos

María

un tiempo de vientos y pájaros

de agachar juntos la cabeza

y caminar con los ojos cerrados

(no es una metáfora es un método)

otro tiempo de aprender la realidad

en su propio fuego

de palmearnos las espaldas

al salir para el combate

de mirarnos de reojo con el objetivo

días de entendernos

de no entendernos nada

caminar por las calles

discutir el comunicado

reírnos a carcajadas

juntos María juntos

realmente fueron otros tiempos

recuerdo una avenida de hojas secas

un gesto de Germán el silencio hosco

de Claudio y los enormes bigotes de Serrucho

mis manos se aferran a las rejas

mi voluntad el futuro inexorable

y ya ves mi nostalgia al pasado

enorme

si llegas a llorar te amo

María...

mas ahora, que ha muerto también Quique

$\mathrm{y}$ sabemos que fueron fusilados. 


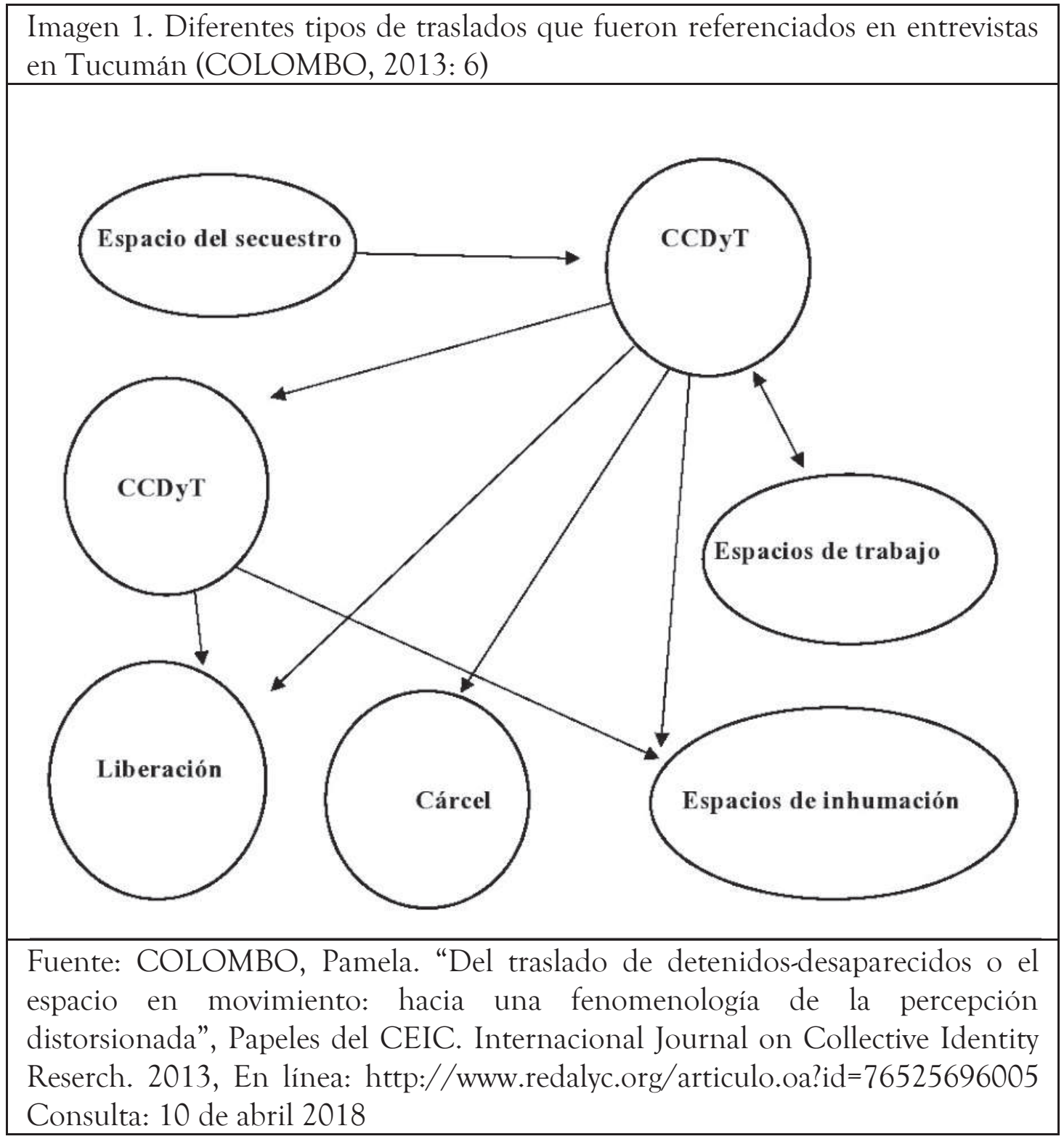




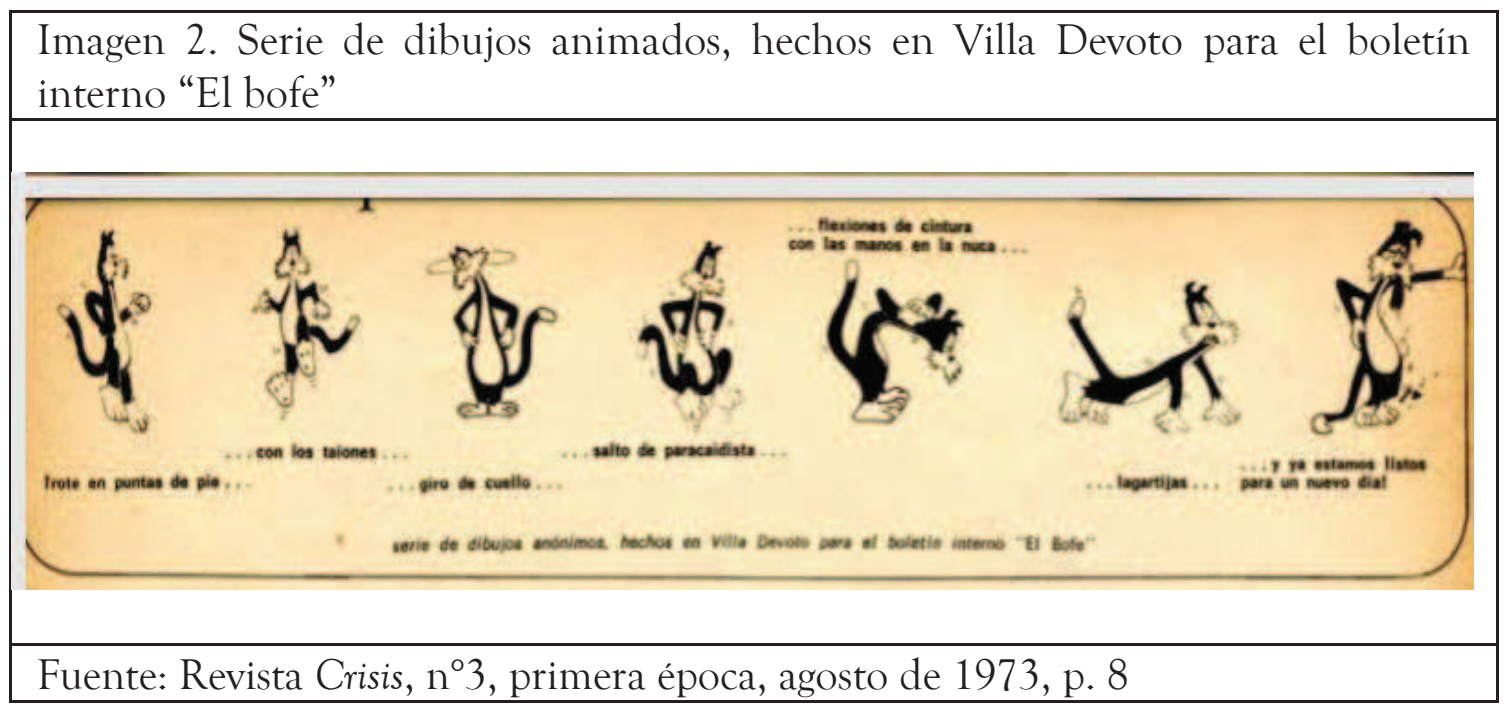


Imagen 3. Dibujo del pintor Franco Venturi prisionero en la celda del buque Granaderos

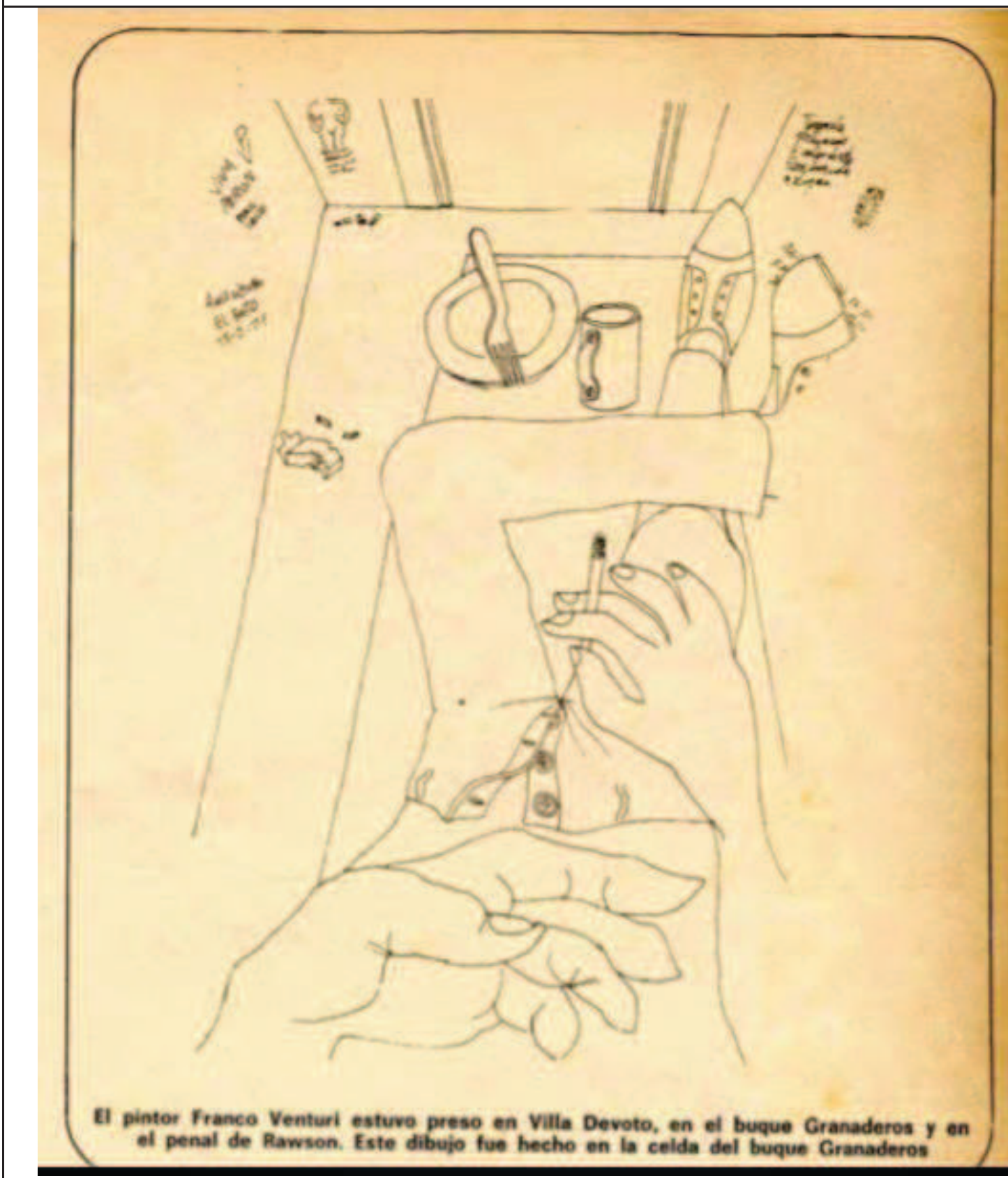

Fuente: Revista Crisis, n³, primera época, agosto de 1973, p. 5 


\section{BIBLIOGRAFÍA}

AVELLANEDA, A. Censura, autoritarismo y cultura: Argentina 1960-1983/ 1 y 2. Buenos Aires: Centro Editor de América Latina, 1986.

BACCI, C. Y OBERTI, A. "DOSSIER: TESTIMONIO: DEBATES Y DESAFÍOS DESDE AMÉRICA LATINA”, CLEPSIDRA, VOL 1, N.

[HTTP://PPCT.CAICYT.GOV.AR/INDEX.PHP/CLEPSIDRA/I SSUE/VIEW/CLEPSIDRA.\%20REVISTA\%2OINTERDISCIPLI NARIA\%20DE\%20ESTUDIOS\%20SOBRE\%20MEMORIA.\%2 OMARZO\%202014.\%20A\%C3\%B1O\%201\%2C\%20N\%C3\%B AMERO\%201, CON ACCESO EL 19/09/2014].

BASCUÑÁN, B. Editores y editoriales en dictadura. Santiago: Museo de la memoria y de los derechos humanos, 2012. [http://www.cedocmuseodelamemoria.cl/wpcontent/uploads/2012/06/Editores-y-editoriales-en-dictadura.pdf, con acceso el 04/10/2013].

BLAUSTEIN, Eduardo y Zubieta, Martín. Decíamos ayer. La prensa argentina bajo el Proceso. Buenos Aires: Colihue, 2006.

BONAVENA, Pablo Augusto. "El movimiento estudiantil frente a la masacre de Trelew del 22 de agosto d 1972”, Conflicto social, a. 4, n. 5, junio 2011: 211-230.

CARBAJAL, Mariana. "El compromiso”, Página12, domingo 24 de julio de 2011. En línea: https://www.pagina12.com.ar/diario/sociedad/3-172914-2011-0724.html Consultado: 10/04/2018.

COHEN IMACH, Victoria. De utopias y desencantos. Campo intelectual y periferia en la Argentina de los sesenta. Tucumán: Universidad Nacional de Tucumán, Facultad de Filosofía y Letras, Instituto Interdisciplinario de Estudios Latinoamericanos, 1994.

COLOMBO, Pamela. "Del traslado de detenidos-desaparecidos o el espacio en movimiento: hacia una fenomenología de la percepción distorsionada", Papeles del CEIC. International Journal on Collective Identity Research. 2013, marzo-sin mes. En línea: 
http://www.redalyc.org/articulo.oa?id=76525696005 Consultado: 10 de abril de 2018.

CORTEZ ERVILHA, G.; Laís de Oliveira, L. y Conde Feitosa, L. M. G. (2009). "O poeta guerrilheiro: Carlos Marighella e o Regime militar (1964-1969)". Em Jornada dos cursos de historia, geografia e arquitetura: "Espaço, história e globalização" (142-152). Anais, 26 a 30 de maio de 2009, Bauru, SP. [http://www.usc.br/biblioteca/pdf/jor_2009_hist_geo_arq.pdf, con acceso 12/10/2013].

D’ANTONIO, Débora y EIDELMAN, Ariel. "El sistema penitenciario y los presos políticos durante la configuración de una nueva estrategia represiva del Estado argentino (1966-1976)", Iberoamericana. América Latina, España, Portugal: Ensayos sobre letras, historia y sociedad, vol. 10, n. 40, 2010, pp. 93-112.

DA SILVA TAVARES, C. (2007). A perspectiva da mulher como resistência às configurações ideológicas do dictador latino-americano: o romance de Julia Alvarez e de Mario Vargas Llosa. Tese de Doutorado en Literatura Comparada. Orientadora: Profa. Dra. Márcia Hoppe Navarro. Porto Alegre: Universidade Federal do Rio Grande do Soul. Instituto de Letras. Programa de Pós-graduação em Letras. Área: Estudos de literatura. Especialidade: Literatura comparada. Linha de pesquisa: Estudos culturais e literários de gênero.

DALMARONI, M. La palabra justa: Literatura, crítica y memoria en la Argentina, 1960-2002. Mar del Plata, Melusina, Santiago: RIL, 2004.

DE ARMAS, G. y GARCÉ, A. Uruguay y su conciencia crítica. Intelectuales y politica en el siglo XX. Uruguay: Trilce. 1997.

DE DIEGO, J. L. "Dictadura y democracia: la crisis de la industria editorial”. En J. L. de Diego (dir.) Editores y políticas editoriales en Argentina (1880-2000) (163-208). Buenos Aires/ México, Fondo de Cultura Económica, 2006

FERNÁNDEZ BENÍTEZ, H. M. "The moment of testimonio is over": problemas teóricos y perspectivas de los estudios testimoniales", 
Íkala, revista de lenguaje y cultura, v. 15, n. 24, enero-abril, 2010: 4771.

FERRARO OSORIO, M. "Los manuscritos de El método y otros juguetes carcelarios". En: C. Liscano. Manuscritos de la cárcel. Edición Fatiha Edmhand. Montevideo: Ediciones del caballo perdido, 2010: 43 58.

FLORES, N. "Dos voces en pugna: la historia oficial como narrativa de legitimación y el relato testimonial chileno 1973-1989”, Cyberhumanitatis: revista de la Facultad de Filosofía y Humanidades, Universidad de Chile, n. 14.2000 [http://www2.cyberhumanitatis.uchile.cl/14/tx15nflores.html, con acceso 19/09/2013].

FRANCO, Jean. Cruel modernity. Durham and Londo: Duke University Press, 2013.

GARAÑO, S. "Entre resistentes e 'irrecuperables': Memorias de ex presas y presos políticos (1974-193)”. Tesis de licenciatura. Directora: Sofía Tiscornia. Carrera: Licenciatura en Ciencias Antropológicas. Orientación sociocultural. Defendida el 25 de marzo de 2008. Facultad de Filosofía y Letras. Departamento de Ciencias Antropológicas. Universidad de Buenos Aires.

GASPARI, E. As ilusões armadas. 2. A ditadura Escancarada. Rio de Janeiro: Editora Intrínseca, 2002.

GEDDES, Jennifer L. "On evil, pain, and beaty: a conversation with Elaine Scarry”, The Hedgehog Review, Summer. 2000:78-87.

GINZBURG, C. "La prueba, la memoria y el olvido", Contrahistorias. La Otra Mirada De Clio, segunda serie, n. 14, México, 2010a, marzo-agosto: 105-116.

GINZBURG, C. El hilo y las huellas. Lo verdadero, lo falso, lo ficticio. Buenos Aires, Fondo de Cultura Económica, 2010b.

GOICOCHEA, A. L. El relato testimonial en la literatura argentina de la literatura de fin de siglo. Tesis de doctorado. Universidad Nacional de La Plata, Facultad de Humanidades y Ciencias de la Educación, 2000 [http://www.memoria.fahce.unlp.edu.ar/tesis/te.5/te.5.pdf, con acceso 17/07/2013]. 
GONZÁLEZ, C.; SCAVINO, D. et Ventura, A. La violence politique dans la culture du Rio de la Plata des années 1960 à nos jours. Bordeux: Ameriber, 2010

GUILLARD, A. "Resistencia y poesía en las cárceles argentinas (19761983)", Amerika, 8. 2013 [http://amerika.revues.org/3904, con acceso 20/06/15].

INVERNIZZI, H. y GOCIOL, J. Un golpe a los libros: represión a la cultura durante la última dictadura militar. Buenos Aires, Eudeba, 2002.

IZAGUIRRE, I. Los desaparecidos: recuperación de una identidad expropiada. Buenos Aires: CEAL, 1994.

JELIN, E. Los trabajos de la memoria. Madrid: Siglo XXI, 2002.

JELIN, E. "Las múltiples temporalidades del testimonio: el pasado vivido y sus legados presentes", Clepsidra. Revista Interdisciplinaria de Estudios sobre Memoria, n. 1, 2014, marzo:140-163.

JOSÉ, E. Carlos Marighella: o inimigo número um da Ditadura Militar. São Paulo: Casa Amarela, 1997.

LERMAN, Gabriel D. La plaza política. Irrupciones, vacíos y regresos en Plaza de Mayo. Buenos Aires: Colihue, 2005.

LISCANO, C. El escritor y el otro. Montevideo: Planeta, 2007

LISCANO, C. Ejercicio de impunidad. El caso Gelman. Buenos Aires: Distal, 2009.

LIZAMA, P. "Las manos al fuego: novela negra, memoria, identidad", Discurso de entrega Premio Fundación José Nuez a José Gai, Taller de Letras, n. 42, 2008: 201-209.

MARTÍNEZ, Tomás Eloy. La pasión según Trelew. Buenos Aires: Granica Editora, 1974.

MENCHÚ, R y BURGOS, E. Me llamo Rigoberta Menchú y así me nació la conciencia. La Habana: Casa de las Américas, 1983.

MORAÑA, M. Memorias de la generación fantasma. Montevideo: Monte Sexto, 1988

PEDRO, J. M. e Scheibe Wolff, C. (Organização) Gênero, Feminismos e Ditaduras no Cone Sul. Florianópolis: Ed. Mulheres, 2010

PINO, M. "Hacia una configuración de los corpus de postgolpes en el cono sur", Universum, n. 15, 2000: 233-240. 
PONZA, Pablo. "Intelectuales, sociedad, literatura y revolución en la revista Crisis: (1973-1976)”. Villa María: Universidad Nacional de Villa María, 2016.

PONZA, Pablo. "Revista Crisis: Primera época (1973-1976). Revisionismo histórico y cultural", Improntas, n. 3, e002, junio-noviembre, 2016: $1-22$.

PORTELA, M. Edurne. "Cicatrices del trauma: cuerpo, exilio y memoria en Una sola muerte numerosa de Nora Strejilevich, Revista Iberoamericana, vol. LXXIV, n. 222, enero-marzo 2009: 1-14.

PRADA OROPEZA, R. "De lo testimonial al testimonio: notas sobre el deslinde del discurso testimonio". En: R. Jara et al (eds.). Testimonio y literatura Minneapolis: Institute for the Study of Ideologies, 1986: 7-21

RICCIO, A. "LO TESTIMONIAL Y LA NOVELA-TESTIMONIO. EL PACTO TESTIMONIAL”, ANALES DE LITERATURA HISPANOAMERICANA, N. 20, 1991:249-262.

ROMÁN, M. "Bibliotecas en el tratamiento penitenciario", Información, cultura y sociedad, n. 16, 2007: 35-54.

Scarry, Elaine. The Body in Pain. Nueva York y Oxford: Oxford UP, 1985.

SEVESO, César. "Escuelas de militancia: la experiencia de los presos políticos en Argentina, 1955-1972”, A contracorriente, vol. 16, n. 3, spring 2009, pp. 137-165.

SONDERÉGUER, María. “Presentación”. En: Revista Crisis (1973-1976). Antología del intelectual comprometido al intelectual revolucionario. Bernal: Universidad Nacional de Quilmes, 2011: 9-26.

STREJILEVICH, N. "Literatura testimonial en Chile, Uruguay y Argentina. 1970-1990". A Thesis submitted in partial fullmiment of the requirement for the degree of doctor of philosophy in The Faculty of Graduate Studies. The University. September, 1991.

SUÁREZ GÓMEZ, J. E. "La literatura testimonial como representación de pasados violentos en México y Colombia: "siguiendo el corte" y "guerra en el paraíso", Revista de Ciencias Sociales de la Universidad Iberoamericana, a VI, n. 11, enero-junio, 2011:57-82. 
TAUZIN CASTELLANOS, I. (coord.). Prisons d'Amérique latine: du réel à la métaphore de l'enfermement (Hommage de l'ERSAL à Yves Aguila). Bordeaux: Presses Universitaires de Bordeaux, coll. Maison des pays ibériques, 2009.

VERBITSKY, H. El vuelo. "Una forma cristiana de morir". Confesiones de un oficial del armada. Buenos Aires: Planeta, 1995.

YÚDICE, G. "Testimonio y concientización". Revista de crítica literaria latinoamericana. La voz del otro: testimonio, subalternidad y verdad narrativa, a. XVIII, 36, 2. ${ }^{\circ}$ semestre, 1992: 207-227.

ZÓ, R. "La violencia dictatorial latinoamericana desde la mirada de Carlos Liscano”. Caderno de letras, n. 26, jan-jun, 2016:179-200 [https://periodicos.ufpel.edu.br/ojs2/index.php/cadernodeletras/ article/view/8824, con acceso 2/10/2016).

ZÓ, Ramiro Esteban. "Ontología del encierro en relatos de una red testimonial iberoamericana", Estudios Interdisciplinarios de América Latina y el Caribe, v. 28, n. 1, 2017: 53-81.

Recebido em: 08/07/2018

Aceito em: 25/07/2018 